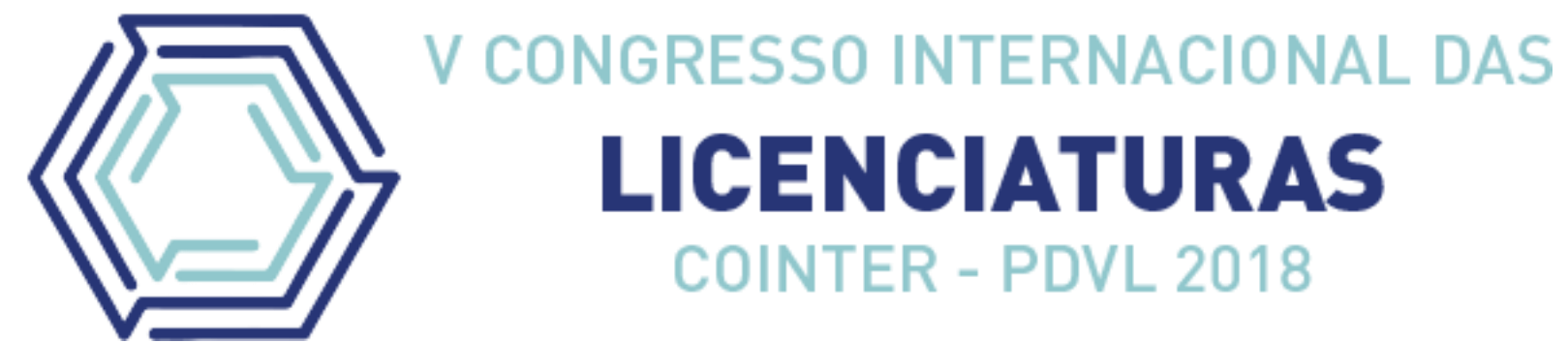

\title{
EDUCAÇÃO INCLUSIVA NO ENSINO DE QUÍMICA: MATERIAIS DIDÁTICOS CRIATIVOS PARA ESTUDANTES COM DEFICIÊNCIA VISUAL
}

\section{INCLUSIVE EDUCATION IN CHEMISTRY: CREATIVE EDUCATIONAL MATERIALS FOR STUDENTS WITH VISUAL DEFICIENCY}

\author{
Apresentação: Relato de Experiência \\ Sérgio Marivaldo dos Santos ${ }^{1}$; Quélia de Souza Sabino ${ }^{2}$; Aldair Lucas Lopes da Silva ${ }^{3}$; \\ Hércules Santiago Silva ${ }^{4}$
}

\section{DOI: https://doi.org/10.31692/2358-9728.VCOINTERPDVL.2018.00274}

\section{Introdução}

O referido trabalho trata-se de um relato de experiência apresentada a estudantes com deficiência visual. O objetivo foi desenvolver um material de fácil utilização para auxiliar alunos cegos e/ou com baixa visão, em comunidades do município de Ipojuca-PE. O material desenvolvido proporcionou aos estudantes entrevistados o contato direto com o material em alto-relevo que podem ser manuseados por estudantes com deficiência visual. O desafio deste trabalho foi superar o modelo de tradicional de sala de aula desenvolvendo um material didático numa perspectiva de Tecnologia Assistivas (TA) que possa facilitar o processo de ensino e aprendizagem de estudantes com deficiência visual promovendo a inclusão e autonomia dos mesmo no ambiente de sala de aula.

PALAVRAS-CHAVE: deficiência visual, Tecnologias Assistivas, gráficos em alto-relevo.

\section{Relato de Experiência}

A metodologia utilizada no presente artigo foi a pesquisa qualitativa em educação voltada para deficientes visuais, sendo produzido um material didático prático, flexível, portátil e de fácil manuseio no ambiente escolar.

Os estudantes com deficiências visuais têm grandes problemas de acesso a materiais didáticos que minimizem as dificuldades inerentes de sua deficiência e melhorem o processo de ensino-aprendizagem (REGIANE; MÓL, 2010).

\footnotetext{
${ }^{1}$ Licenciatura em Química, IFPE Campus Ipojuca, sergiomarivaldo@hotmail.com

${ }^{2}$ Licenciatura em Química, IFPE Campus Ipojuca, queliasabino@hotmail.com

${ }^{3}$ Licenciatura em Química, IFPE Campus Ipojuca, allucassilva2709@gmail.com

${ }^{4}$ Mestre em Química, IFPE - Campus Ipojuca FPE, herculessantiago@ipojuca.ifpe.edu.br
} 
A escassez de materiais didáticos para esse público dificulta o processo de integração desses estudantes e a socialização do conhecimento no ambiente da sala de aula. Essa dificuldade de acesso a materiais para essa parcela de estudantes aflige os docentes em sala de aula, pois essa ausência acaba por precarizar e dificultar a socialização do conhecimento. Embora, na maioria das vezes, isso não ocorra a despeito da boa vontade do professor, mas pela inexistência desses materiais nas redes de ensino.

[ ]E nem sequer se trata, na maior parte dos casos, de má vontade por parte do professor ou indisponibilidade do aluno portador de deficiência. Trata-se, tãosomente, da dificuldade de efetivar, na prática, a "Escola Inclusiva", tão sabiamente arquitetada de formas teóricas, à luz da nossa bem intencionada legislação. (PEREIRA, 2003).

Segundo Favero et al (2009), a produção de materiais educacionais para estudantes com deficiência tem grande impacto didático e social. Para tanto, o material desenvolvido precisa ser de fácil entendimento, fácil percepção através do tato e que mantenha sua integridade durante todo processo de análise pelo estudante com deficiência visual. Daí a ideia do uso de um material maleável, moldável e que fosse possível produzi-lo com materiais de baixo custo e/ou de materiais reciclados.

O material didático desenvolvido foi composto de um quadro branco em chapa metalizada e com fitas magnéticas reaproveitadas de uma geladeira em estado de sucata. Nesse quadro é possível reproduzir gráficos de funções e equações matemáticas, de física, química e das mais diversas disciplinas do ensino básico, pois são flexíveis, práticos e apresentam alto-relevo tornando-os acessíveis a estudantes cegos ou com algum grau de deficiência visual facilitando o processo de ensino-aprendizagem.

Na Imagem 1.1 é possível visualizar o quadro de chapa metalizada e fios magnéticos que foram obtidos em sucatas de geladeiras e cortados em vários tamanhos diferentes para produzir os mais diversos gráficos possíveis:

Através deste material é possível desenvolver qualquer tipos de gráficos, como os de mudanças de estados físicos da matéria (1.3 e 1.4), funções matemáticas (1.5 e 1.6) e até mais de um gráfico numa mesma área (1.2) dentre várias aplicações didáticas. O estudante com deficiência visual, com auxílio do tato, consegue "visualizar" e construir os gráficos de forma autônoma, facilitando a socialização do conhecimento e sua devida construção de forma mais 
efetiva que os métodos tradicionais.

Imagem 1: Gráficos Construídos com o Material Didático. Fonte: Própria

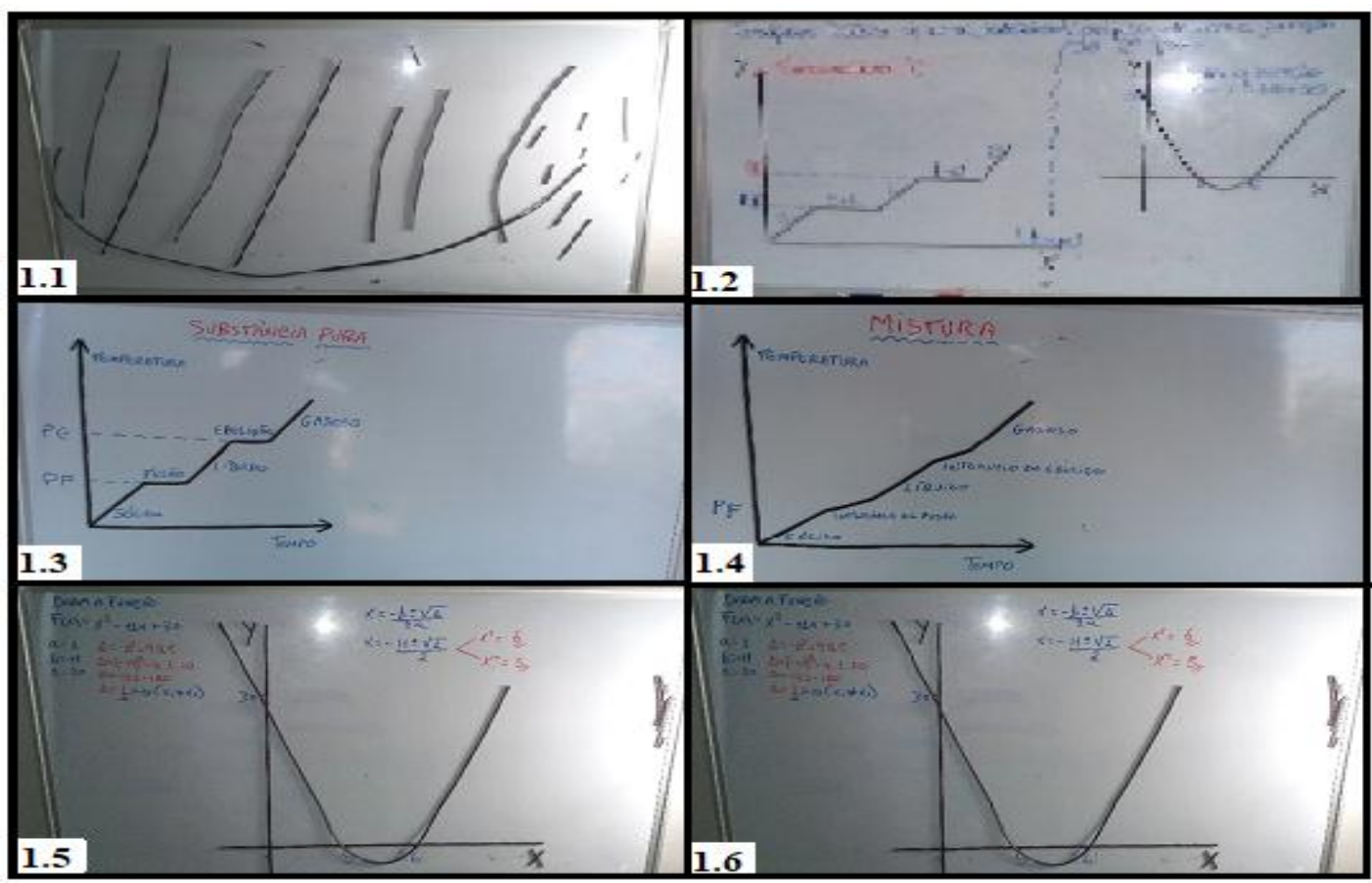

O ferramenta didática produzida foi apresentada para estudantes sem problemas visuais (Imagem 2) que, com os olhos vendados tatearam os gráficos e puderam se inserir no "mundo" dos deficientes visuais e perceber suas dificuldades e desafios na construção do conhecimento.

Imagem 2: Uso do Material Didático por Estudantes sem Deficiência Visual. Fonte: Própria 


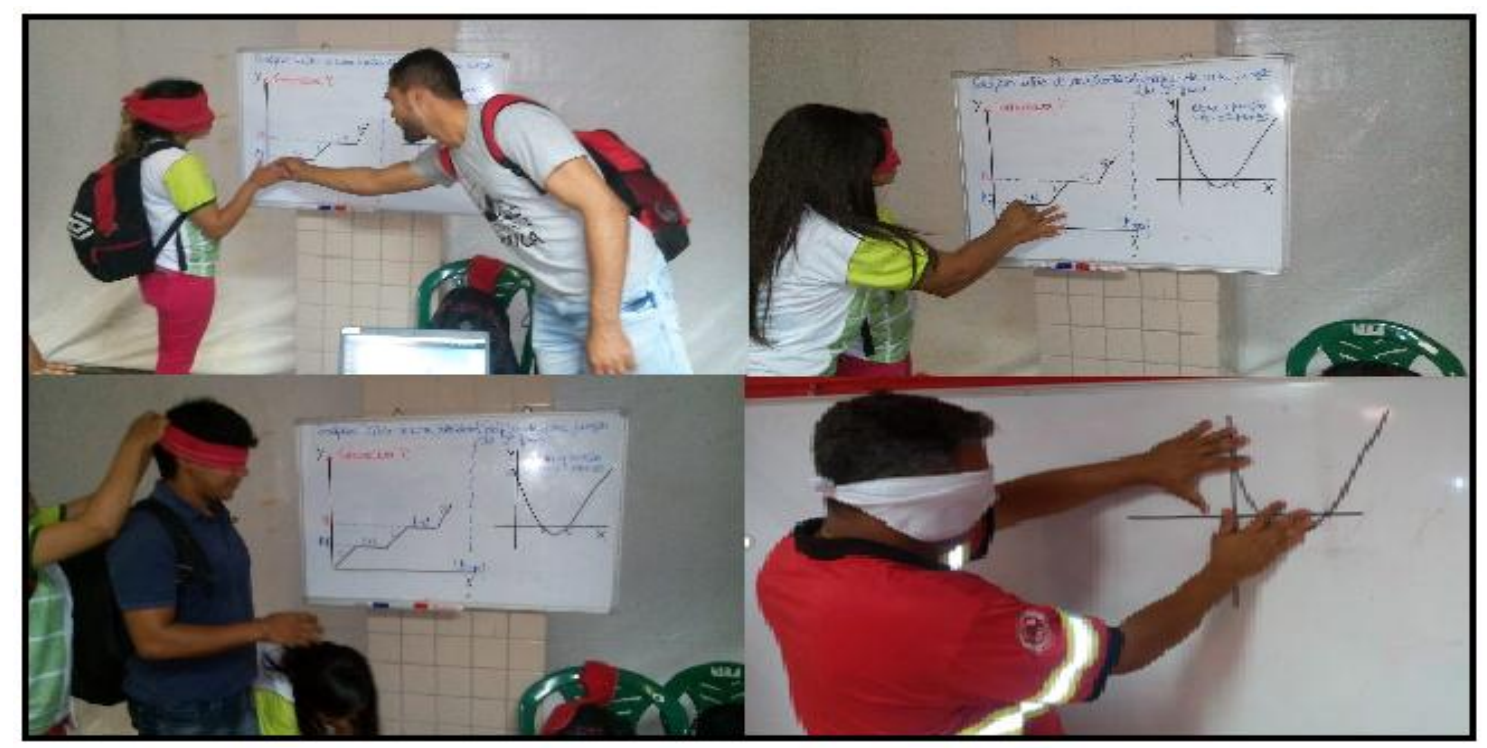

O material didático foi apresentado para um estudante com deficiência visual e lhe foi apresentado um questionário com três perguntas relacionadas ao material didático que foi utilizado por ele e esse estudante avaliado positivamente o material didático:

Tabela: Questionário de avaliação do material didático.

\begin{tabular}{|c|c|}
\hline PERGUNTAS & RESPOSTAS \\
\hline $\begin{array}{l}\text { 1) O que você achou do material } \\
\text { didático? }\end{array}$ & Muito interessante. \\
\hline $\begin{array}{l}\text { 2) O objetivo desse material didático é } \\
\text { facilitar o entendimento de gráficos para } \\
\text { deficientes visuais. Esse objetivo foi } \\
\text { atingido? }\end{array}$ & Sim, positivamente. \\
\hline $\begin{array}{l}\text { 3) Se sua resposta anterior foi sim, essas } \\
\text { facilidades despertaram interesse por } \\
\text { assuntos relacionados? }\end{array}$ & $\begin{array}{l}\text { Sim, esse material poderia ser adaptado em } \\
\text { sala de aula para que as pessoas que não } \\
\text { conseguem enxergar o tenha acesso direto } \\
\text { com o gráfico no qual foi desenvolvido por } \\
\text { ele mesmo. }\end{array}$ \\
\hline
\end{tabular}

\section{Considerações}

O material didático produzido se mostrou bastante promissor e pertinente no que se diz respeito às políticas educacionais inclusivas. $\mathrm{O}$ estudante com deficiência visual que usou o material avaliou que o mesmo foi bastante eficiente. Nesse cenário podemos destacar que a boa aplicação desta ferramenta poderá ajudar no estudo de gráficos nas mais diversas áreas de conhecimento para deficientes visuais, cegos e com baixa visão, focando no estudo de gráficos táteis. Como perspectivas futuras, pretendemos aplicar o método para outros estudantes e inserir escalas numéricas em Braille para que seja possível o uso do sistema de coordenadas gráficas de forma mais efetiva. 


\section{Referências}

PEREIRA, F. M. A Deficiência Visual no Ensino Regular. Millenium Online. Lisboa. Portugal: 2003.

REGIANE, A.M.; MÓL, G.S Inclusão de uma aluna cega num curso de Licenciatura em Química. Cidade e Educação. Brasília: 2010.

FAVERO, O.; FERREIRA, W.; IRELAND, T.; BARREIROS, D. Educação Inclusiva. UNESCO. Brasília: 2009. 